\title{
System dynamics model for hospital waste characterization and generation in developing countries
}

\author{
Derar Eleyan ${ }^{1}$, Issam A. Al-Khatib ${ }^{2, *}$, Joy Garfield ${ }^{3}$ \\ ${ }^{1}$ Information Systems, Birzeit University, West Bank, Palestine. \\ ${ }^{2}$ Institute of Environmental and Water Studies, Birzeit University, West Bank, Palestine. \\ ${ }^{3}$ Informatics Department, School of Technology, University of Wolverhampton, \\ Wolverhampton, United Kingdom.
}

*Corresponding Author: Issam A. Al-Khatib, Institute of Environmental and Water Studies,
BirzeitUniversity, P.O. Box 14, Birzeit, West Bank, Palestine.
E-mail: ikhatib@birzeit.edu; ikhatib2012@yahoo.com, Fax: 009722-2982120.

\begin{abstract}
Waste management policy makers always face the problem of how to predict the future amount and composition of medical solid waste, which in turn will help determine the most appropriate treatment, recycling and disposal strategy. An accurate prediction can assist in both the planning and design of medical solid waste management systems. Insufficient budget and unavailable management capacity are the main reasons for the scarcity of medical solid waste quantities and components historical records, which are so important in long-term system planning and short-term expansion programs. This paper presents a new technique, using system dynamics modeling, to predict generated medical solid waste in a developing urban area, based on a set of limited samples from Jenin District hospitals, Palestine. The findings of the model present the trend of medical solid waste generation together with its different components and indicate that a new forecasting approach may cover a variety of possible causative models and track inevitable uncertainties when traditional statistical least-squared regression methods are unable to handle such issues.
\end{abstract}


Keywords: hospital waste, generation rate, characterization, system dynamics, developing countries 


\section{Introduction}

Although healthcare is important in every country, various types of waste are generated that may have adverse effects on human health and the environment (Chaerul et al., 2008; Birpinar et al., 2009). Hospital waste generated from healthcare activities can be classified into two major groups; general waste and hazardous waste. The majority of waste, which is 75 to $90 \%$ of the waste produced by healthcare, is non-risk or general waste that is comparable with domestic or municipal solid waste (Pruss et al., 1999; Karamouz et al., 2007; Chaerul et al., 2008).As general waste is not regulated or defined as hazardous or potentially dangerous waste, it requires no special handling, treatment or disposal (Lee et al., 2004). As such it should be dealt with via municipal waste disposal mechanisms (Pruss et al., 1999; Farzadkia et al., 2009). The remaining 10 to $25 \%$ of healthcare waste is regarded as hazardous or special waste, according to definitions given by the World Health Organization (WHO) and US Environmental Protection Agency (US EPA).

The hazardous or special waste materials consist of infectious waste, pathological waste, geno-toxic waste, pharmaceutical waste, chemical waste, waste with high heavy metal content, pressurized containers and radioactive waste, most of which are toxic, harmful, carcinogenic and infectious materials (Pruss et al., 1999; Marinkovic et al., 2008; Cheng et al., 2010;). These types of hospital waste need to be properly managed which is warranted so that the impact on the public health and the environment is maintained at a minimum (Chaerul et al., 2008). Although the proportion of infectious and hazardous waste is relatively small, any improper waste management, where infectious waste is mixed with general waste, can render all the waste potentially infectious and hazardous (Chaerul et al., 2008; Cheng et al., 2009).

Generation of solid waste in hospitals depends on many factors, such as the type of healthcare establishment, the level of instrumentation and location. According to Hamoda et al. (2005), Mohee (2005) and Sawalem et al. (2009), developing countries have low waste generation rates when compared to industrialized countries in Europe or the Americas. The difference is consistent with different living habits and standards and is due to the availability of treatment facilities. 
The accurate calculation of the unit generation rates and composition of hospital waste generated from medical facilities is necessary in order to design hospital waste treatment and management systems (Diaz et al., 2008). The problems associated with hospital waste treatment exist at all levels, namely collection, segregation, transport and storage (Stanković et al., 2008). All the techniques for the treatment of hazardous hospital waste have both advantages and disadvantages. The choice of technique should not be based on economic characteristics but rather on safety characteristics that will enable reliable care of both human health and the environment. Proper management of hospital waste requires the careful separation of the hospital waste stream, since a different treatment technique is expected to be suitable for each fraction (Bdour et al., 2007; Komilis et al., 2011).

\section{Methodology}

\section{Hospital waste Generation Rate and Characterization}

A survey of Jenin city hospitals in the North West Bank, Palestine was conducted. The survey was designed to collect data about health care waste in government, private and NGO hospitals. A letter was sent to the head of each hospital to solicit their collaboration and support. Site visits were conducted at all selected hospitals to gather the basic information and assess working conditions in addition to other administrative arrangements. In the study, the classification criteria was based on potential risks and divided into two categories: medical and general waste. Hospital waste was divided into tissue and pathological waste, absorbent cotton items, discarded medical plastic, waste sharps and waste mixed with infectious waste. General waste was also categorised into metals, paper and cardboard, plastics, textiles, glass and others.

Waste from the hospitals was separated into its different components with a high level of precision by the survey team. The quantities $(\mathrm{Kg} /$ day) and rate of waste generation $(\mathrm{Kg} / \mathrm{bed} /$ day) of medical and general solid waste were recorded outside the hospital building. Solid waste of both types (general and medical) was weighed individually on a suspension spring scale $( \pm 100 \mathrm{~g})$ with the assistance of the staff and the weight was recorded by the field workers. The categories were weighed separately and results recorded. Finally, data forms were completed and stored for further analysis. The data was analyzed using statistical Excel. The amount of general and hospital waste 
materials generated in each hospital was determined and recorded for each day over seven consecutive days during March, April and May 2011.

A system dynamics methodology was developed to predict amounts of waste which will have accumulated in a couple of years' time. This information could be used by the government and interested parties to take further action regarding recycling, disposal and the potential impact on public health.

\section{System Dynamics Methodology}

Jay Forester introduced the System Dynamics approach in the 1960s at Massachusetts Institute of Technology. This approach is used as a modelling and simulation methodology for long-term decision-making analysis of management problems such as waste management, which is the theme of this paper. It helps modellers and decision makers to conceptualize and rationally analyse the structure, interactions and mode of behaviour of complex systems and sub-systems to explore, assess and prognosticate their impacts in an integrated, holistic manner (Chaerul, 2008).

System dynamics has the ability to deal with assumptions about system configuration and structures in a stringent way, and facilitate the monitoring and control of the effects of changes in subsystems and their relationships. System dynamics is also differentiated from simple spreadsheet packages as it offers a more quantitative, sophisticated simulation and is capable of more robust and reliable outcomes by generating mathematical equations to perform the required calculations (Kollikkathar et al., 2010). As computer-assisted decision making in the public policy field has become more common in recent years, with policymakers facing increasing demands for accountability, many software packages have become commercially available to facilitate modelling using the system dynamics theme (Rubenstein-Montano and Zandi, 2000).

A causal loop diagram is a system dynamics technique used to capture major feedback mechanisms, as shown simply in Fig. 1. The diagram includes variables and arrows (causal links) linking these variables together in the same manner and a sign (either + or -) on each link. These signs have the following meanings: 
- The causal link between waste and waste recycled is positive which means that as the waste generated increases then the waste recycled will increase, as it depends on the amount of waste generated.

- The causal link between waste recycled and waste is negative which means that, as the waste recycled increases, it will cause the waste to decrease.

In addition to the sign of each causal link between any successive variable, the whole loop is also given a sign. If the sum of negative signs in a loop is even then whole loop is given a positive sign, which means the loop is reinforcing and the system is in unstable equilibrium (exponential growth). On the other hand, if the sum of negative signs is odd, as in Fig.1 above, then the whole loop is assigned with a negative sign which means the loop is balancing and the system seeks to return to an equilibrium situation.

After the casual loop is generated for a whole system and encompasses all of the required variables, the next step in system dynamics modelling is to convert the generated causal loop diagram into a process model, called a stock and flow diagram, as shown in Fig. 2.

A system dynamics model is constructed by the building blocks of four main types, namely stocks, flows, connectors, and converters (Fig. 2). Stock variables (symbolized by rectangles) are the state variables and they represent the major accumulations in the system. Flow variables (symbolized by valves) are the rate of change in stock variables and they represent those activities that fill in or drain the stocks. Converters (represented by circles) are intermediate variables used for miscellaneous calculations. Finally, the connectors (represented by simple arrows) are the information links representing the cause and effects within the model structure. Fig. 2 shows that of the quantity of waste generated (Flow1), the quantity of waste recycled (Flow2) depends on the recycling rate (Converter) and the total quantity of the waste accumulated (Stock).

The system dynamics model is built using high-level graphical simulation software, think 8.0 simulation tool, which is one of the famous simulation modelling soft wares 
used in system dynamics (such as ithink ${ }^{\circledR}$, Stella ${ }^{\circledR}$, Vensim $®$, and Powersim ${ }^{\circledR}$ ) to support the analysis and study of these systems.

Using ithink software a mathematical mapping of a system dynamics stock-flow diagram can be automatically generated via a system of differential equations, which is solved numerically via simulation. The stock and flow model is used to simulate different situation scenarios to explore the optimal situation and switch all of the variables accordingly to the values which generate the situation.

A variety of different systems which consider feedback systems can be modelled using System dynamics modelling. For example, business systems, ecological systems, socialeconomic systems, agricultural systems, political decision making systems and environmental systems, including waste management systems, can be addressed using system dynamics methodology (Dyson and Chang, 2005). In relation to environmental concerns, system dynamics modelling has been applied to a number of issues, including salt accumulation in lowlands under continuous irrigation practice (Saysel and Barlas, 2001); value of water conservation (Stave, 2003); the consequences of dioxin to the supply chain of the chicken industry (Minegishi and Thiel, 2000); the eutrophication problem in shallow freshwater lakes (Guneralp and Barlas, 2003); the impact of environmental issues on long-term behaviour of a single product supply chain with product recovery (Georgiadis and Vlachos, 2004); sustainability of ecological agricultural development at a county level (Shi and Gill, 2005); estimation of methane emissions from rice Welds (Anand et al., 2005); basin's environmental management system (Guo et al. 2001); and waste management (Dyson and Chang, 2005; Ulli-Beer, 2003; Karavezyris et al., 2002; Sudhir, et al. 1997).

\section{System Dynamics Model of Hospital General and Hospital wastes}

As far as waste management is concerned, more attention needs to be paid to hospital waste management and the prediction of its generation, as it plays an important role in the waste management system. Traditional forecasting methods frequently rely on demographic and socioeconomic factors on a per-capita basis. In order to forecast the solid waste generation of a complex waste management system, a system dynamic model has been proposed in this paper.The stock and flow model in Fig. 3 represents the 
hospital medical and general waste management model. This model encompasses two main types of waste generated: general waste and hospital waste. It is an abstract and conceptual model focused on selected elements and hypotheses of their interactions. The dynamics of the model are determined by the feedback of the stock and flow model.

Hospital and general waste generation would be directly proportional to the population and the number of beds available for the community. This model provides segregation to hospital waste and displays separated quantities of both infectious and general waste. The performance of the waste segregation process depends on the knowledge of the hospitals' staff at the points of generation. The collected waste is treated (in the case of infectious waste) and disposed of at a final disposal site, but the increasing disposal rate will certainly shorten the lifetime of the disposal site.

This model also segregates general and hospital waste into their original components. For example, general waste is segregated into textiles, plastics, glasses, paper and cardboard and metals. Hospital waste is segregated into discarded medical plastics, tissues and pathological waste, infectious, absorbent cotton items and waste sharps.

The model shown in Fig. 3 has been simulated and tested using real data obtained from Jenin city, which is located at the north of Palestine. The population of Jenin is 256,000 persons and the annual growth rate is $2.9 \%$. The total number of beds considered is 57 which is equivalent to one bed for every 4492 persons. The model also calculated the total cost of hospital waste treatment according to the following equation by considering the Medical Waste Treatement Cost of 0.9 \$US per Kg.

Total cost of treatment $=$ Med_Waste_Treatment_Cost*Total_Med_Waste 


\section{Results and Discussion}

Tables 1, 2 and 3 show the mean values of generated medical, general and total hospital wastes respectively in terms of gbed ${ }^{-1} \mathrm{day}^{-1}$, gin-patient ${ }^{-1}$ day $^{-1}$, gtotal patients ${ }^{-1}$ day $^{-1}$ and gemploye $^{-1}$ day $^{-1}$ in the surveyed hospitals. Waste mixed with infectious waste was the largest component of hospital waste, which was approximately $0.4 \mathrm{Kgbed}^{-1} \mathrm{day}^{-1}$, while pathological waste was the smallest component, being approximately $0.002 \mathrm{Kg}^{-}$bed $^{-}$ ${ }^{1} \mathrm{day}^{-1}$. The mean value of total hospital waste was approximately $0.85 \mathrm{Kg} \mathrm{bed}^{-1} \mathrm{day}^{-1}$. When considering the total number of patients attending the hospitals, the generation rate is much less than that when considering only in-patients, as the number of outpatients attending the external clinics in the hospitals is high. For example, in Al-Razi hospital during the field work, it was found that the number of outpatients ranged from 87 to 250 , while the number of inpatients ranged from 8 to 15 . These are the main sources of hospital waste and normally little waste is generated during consultations/treatment.

Regarding the hospital waste generation rate, plastics were the largest component generated at hospitals, with a mean value of approximately $0.37 \mathrm{Kg} / \mathrm{bed} / \mathrm{day}$, while metals were the smallest value, approximately $5 \mathrm{gbed}^{-} \mathrm{day}^{-1}$. The mean value of total general waste at the three hospitals was approximately $1.12 \mathrm{Kg} \mathrm{bed}^{-1} \mathrm{day}^{-1}$ and the mean total hospital waste generation rate was approximately $1.96 \mathrm{Kg} \mathrm{bed}^{-1} \mathrm{day}^{-1}$.

These results were compared with the generation rates determined in other studies from different countries, as shown in Table 4. This table indicates that the generation rate of hospital waste differs not only from country to country but also within countries. For example, in Iran, the generation rate ranged between $2.75-4.58 \mathrm{Kg} \mathrm{bed}^{-1} \mathrm{day}^{-1}$ and in Palestine between $1.86-2.3 \mathrm{Kg} \mathrm{bed}^{-1} \mathrm{day}^{-1}$.

The variation in waste generation among hospitals may be attributed to a variety of reasons, such as the type of healthcare establishment, income level, welfare of patients and visitors, diversity of departments (for example, surgical, general, pediatric, etc.), type of hospital in terms of private or public, level of instrumentation and location, hospital specialization, proportion of disposable substance used in healthcare activities 
and efficiency of segregation of the hazardous hospital waste from the non-hazardous hospital waste stream. It is also reported that the range of generation rate values for countries of similar income levels probably is as wide in high-income countries as in less wealthy countries (WHO, 1999).

Societies are continually looking to improve their public and private health care services and there are various ways in which this can be achieved. However, besides their benefits, healthcare services generate a number of different types of wastes which can have bad effects on the environment and human health. Therefore, proper management of healthcare waste is needed to minimize the impact on public health and the environment. Relatively large quantities of waste with a broad range of compositions and characteristics can be generated by healthcare establishments, such as hospitals. Such waste carries a higher potential for injury, infection and environmental pollution than any other type of healthcare waste (WHO, 2001, 2004). Chaerul (2008) shows that between $75 \%$ and $90 \%$ of hospital waste is non-risk or 'general' healthcare waste, analogous to municipal solid waste (MSW). Table 5 supports these percentages and shows around $41 \%$ of hospitals' waste in Palestine are hospital wastes, $21 \%$ of them are medical infectious and 3\% are waste sharps. Although the proportion of infectious and hazardous waste is relatively small, improper waste management in which infectious waste is mixed with general waste can contaminate all of the waste.

Although hospital waste poses potential health risks, a safe and reliable infrastructure for their management is not available in most developing countries, such as in Palestine. Table 5 shows a prediction of twenty years of total hospital waste, total general waste and total waste which is the sum of total hospital waste and total general waste. For example, the total waste generated in the first year is $33,808.07 \mathrm{Kg}, 14,189 \mathrm{Kg}$ being hospital waste, while $19,618 \mathrm{Kg}$ is general waste. After ten years, the table shows that the total waste generated will be $304,369.36 \mathrm{Kg}, 127,746.41 \mathrm{Kg}$ being hospital waste. This information would put the policy makers in a better position to plan for medical solid waste management. 
Figure 4 shows the annual hospital waste generation rate and its components (e.g. absorbent cotton, plastic medical infectious). The graph shows that increases in the different rates are consistent with the number of beds.

Table 6 shows the total cost of hospital waste treatment, which helps in predicting the total costs in a number of years. For example, the total cost of treatment in year 19 will be $\$ 296,333.01$ according to the equation of Total cost of treatment.

\section{Conclusions}

Most developing countries and Palestine, used as an example in this paper, are experiencing increases in the quantity and variety of the generation of hospital waste. Therefore, the management of such waste has been a major concern due to the potentially high risks to human health and the environment as a whole.

It is clear from past experience that estimations of medical solid waste generation is crucial for solid waste management planning in a metropolitan region, from both shortterm and long-term perspectives. However, a complete record of medical solid waste composition and generation is not always available. This paper puts forward an effective method, using system dynamics modeling, for tackling forecasting problems. Other techniques tend to lack the utilization of significant amounts of data for determining regression models and have vague relationships between dependent variables and socio-economic factors. The system dynamics model was developed for the prediction of medical solid waste generation in a developing area of Palestine, Jenin District. Additionally the model is used as a planning model, which was considered based on an assumption that the existing population growth rate will remain in the entire planning horizon. Thus, the system will constantly maintain the same trend in generation rate and the same percentage of the different components. The modelling results are useful for associated system planning with regard to future site selection and capacity planning of medical solid waste.

The system dynamics model has the potential to predict future generated quantities of different hospital waste components and assess the cost of treatment. Solid waste management has interwoven and interdependent issues, which are addressed in this 
paper from a system perspective. Finally, this paper shows that the model can be used as a tool or resource to support hospital waste management policy analysis. It provides a prediction of future generated quantities of each component and enables policy makers and planners to be in a better position to understand a situation and setup plans to alleviate negative consequences and effects in both human health and the environment. 


\section{References}

Abdulla F, Qdais HA and Rabi A (2008) Site investigation on medical waste management practices in northern Jordan. Waste Management 28: 450-458.

Al-Khatib IA, Al-Qaroot YS and Ali-Shtayeh MS (2009) Management of healthcare waste in circumstances of limited resources: A case study in the hospitals of Nablus city Palestine. Waste Management \& Research 27: 305-312.

Anand S, Dahiyaa RP, Talyana V and Vratb P (2005) Investigations of methane emissions from rice cultivation in an Indian context. Environment International 31: 469-482.

Askarian M, Vakili M and Kabir GH (2004) Results of a medical waste survey in private hospitals in Fars province Iran. Waste Management 24: 347-352.

Bazrafshan E and Mostafapoor F K (2011)Survey of medical waste characterization and management in Iran: A case study of Sistan and Baluchestan Province. Waste Management \& Research 29(4): 442-450.

Bdour A, Altrabsheh B, Hadadin N and Al-Shareif M (2007) Assessment of medical wastes management practice: A case study of the northern part of Jordan. Waste Management 27: 746-759.

Birpinar ME, Bilgili MS and Erdogan T (2009) Medical waste management in Turkey: A case study of Istanbul. Waste Management 29: 445-448.

Chaerul M, Tanaka M and Shekdar AV (2008) A system dynamics approach for hospital waste management. Waste Management 28(2): 442-449.

Cheng YW, Li KC and Sung FC (2010) Medical waste generation in selected clinical facilities in Taiwan Waste Management 30: 1690-1695.

Cheng YW, Sung FC, Yang Y, Lo YH, Chung YT and Li KC (2009) Medical waste production at hospitals and associated factors. Waste Management 29 440-444

Da Silva C, Hoppe A, Ravanello M and Mello N (2005) Medical waste management in the South of Brazil. Waste Management 25: 600-605.

Diaz LF Eggerth LL Enkhtsetseg SH and Savage GM (2008) Characteristics of healthcare wastes. Waste Management 28: 1219-1226.

Dyson B and Chang NB (2005) Forecasting municipal solid waste generation in a fastgrowing urban region with system dynamics modelling. Waste Management 25: 669679.

Farzadkia M, Moradi A and Shah Mohammadi M (2009) Hospital waste management status in Iran: A case study in the teaching hospitals of Iran University of Medical Sciences. Waste Management \&Research 27: 384-389. 
Georgiadis P and Vlachos D (2004) The effect of environmental parameters lon product recovery. European Journal of Operational Research 157:449-464.

Guneralp B and Barlas Y (2003) Dynamic modeling of a shallow freshwater lake for ecological and economic sustainability. Ecological Modeling 167: 115-138

Guo HC, Liu L, Huang GH, Fuller GA, Zou R and Yin YY (2001) A system dynamics approach for regional environmental planning and management: a study for the Lake Erhai Basin. Journal of Environmental Management 61: 93-111.

Hamoda HM, El-Tomi HN and Bahman QY (2005) Variation in hospital waste quantities and generation rates. Journal of Environmental Science and Health A40 467-476.

Karamouz M, Zahraie B, Kerachian R, Jaafarzadeh N and Mahjouri N (2007) Developing a master plan for hospital solid waste management: A case study. Waste Management 27: 626-638.

Karavezyris V, Timpe KP and Marzi R (2002) Application of system dynamics and fuzzy logic to forecasting of municipal solid waste. Mathematics and Computers in Simulation 60: 149-158.

Kerdsuwan S (2000) Case study of using hospital waste incinerator in Thailand. In Proceedings of the 93rd Annual Meeting and Exhibition pp 18-22 Air \& Waste Management Association Salt Lake City, UT, USA.

Kollikkathara N, Feng H and Yu D (2010) A system dynamic modeling approach for evaluating municipal solid waste generation landfill capacity and related cost management issues. Waste Management 30: 2194-2203.

Komilis D, Katsafaros N and Vassilopoulos P (2011) Hazardous medical waste generation in Greece: case studies from medical facilities in Attica and from a small insular hospital. Waste Management \& Research 29(8): 807-814.

Lee BK, Ellenbecker MJ and Moure-Ersaso R (2004) Alternatives for treatment and disposal cost reduction of regulated medical wastes. Waste Management 24: 143-151

Marinkovic N, Vitale K, Holcer NJ, Dzakula A and Pavic T (2008) Management of hazardous medical waste in Croatia. Waste Management 28: 1049-1056.

Masoumbeigi H, Karimi-zarchi A and Tajik J (2008) Survey of solid waste situation in the specialist hospital in Tehran with emphasis on quantity of waste production. Journal of Military Medicine 9: 129-138.

Minegishi S and Thiel D (2000) System dynamics modeling and simulation of a particular food supply chain Simulation. Practice and Theory 8: 321-339. 
Mohee R (2005) Medical waste characterisation in healthcare institutions in Mauritius. Waste Management 25: 575-581.

Pruss A, Giroult E and Rushbrook P (1999) Safe Management of waste from healthcare activities. Geneva Switzerland: World Health Organization.

Rubenstein-Montano B and Zandi I (2000) An evaluative tool for solid waste management. Journal of Urban Planning and Development, ASCE 1263: 119-135.

Sawalem M, Selic E and Herbell JD (2009) Hospital waste management in Libya: A case study. Waste Management 29: 1370-1375.

Saysel AK and Barlas Y (2001) A dynamic model of Stalinization on irrigated lands. Ecological Modeling 139: 177-199.

Shi T and Gill R (2005) Developing effective policies for the sustainable development of ecological agriculture in China: the case study of Jinshan County with a systems dynamics model. Ecological Economics 53: 223-246.

Shen BH, Wang X,Ch Li JSh and Zhang YH (2003) Current situation and disposing countermeasure of medical waste in Jilin province, China. Environmental Management 22: $35-36$.

Stave KA (2003) A system dynamics model to facilitate public understanding of water management options in Las Vegas Nevada. Journal of Environmental Management 67: 303-313.

Sudhir V, Srinivasan G and Muraleedharan VR (1997) Planning for sustainable solid waste management in urban India System Dynamics Review 13: 223-246.

Stanković A, Nikić D and Nikolić M (2008) Report: Treatment of medical waste in Nišava and Toplica districts Serbia. Waste Management \& Research 26: 309-313.

Taghipour H and Mosaferi M (2009) Characterization of medical waste from hospitals in Tabriz, Iran. Science of the Total Environment 407: 1527-1535.

Tsakona M, Anagnostopoulou E and Gidarakos E (2007) Medical waste management and toxicity evaluation: a case study. Waste Management 27: 912-920.

Ulli-Beer S (2003) Dynamic interactions between citizen choice and preferences and public policy initiatives - A system dynamics model of recycling dynamics in a typical Swiss locality. Proceedings of the 2003 International Conference of the System Dynamics Society New York City USA 20-24 July 2003.

WHO (1999) In: Prues A Giroult E Rushbrook P (Eds) Safe management of wastes from health-care activities. World Health Organization, Geneva. 
WHO 2001 Review of health impacts from microbial hazards in health care wastes (Draft) Prepared by Salkin IF. In: Kennedy ME (Ed) World Health Organization Geneva.

WHO 2004 Preparation of national health-care waste management plans in sub-Saharan countries: guidance manual. Prepared by World Health Organization and the Secretariat of the Basel Convention World Health Organization. 


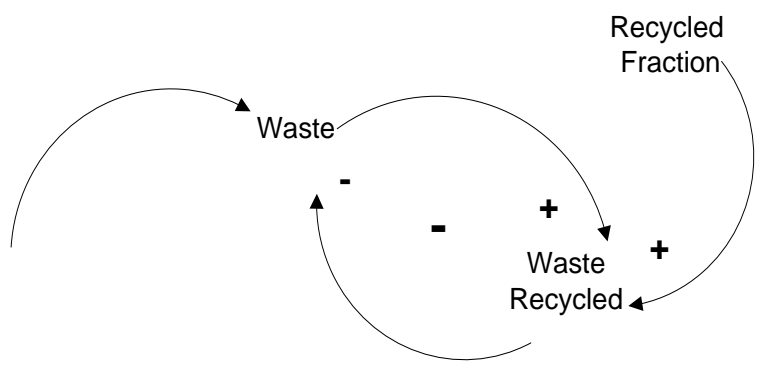

Figure 1.Waste causal loop diagram.

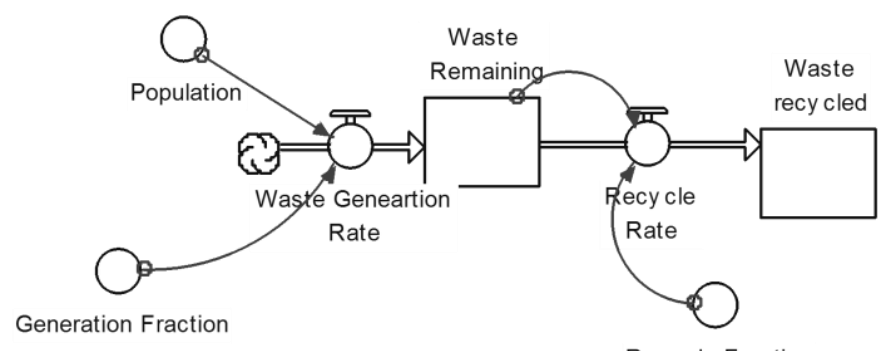

Recy cle Fraction

Figure 2.Waste stock and flow diagram 


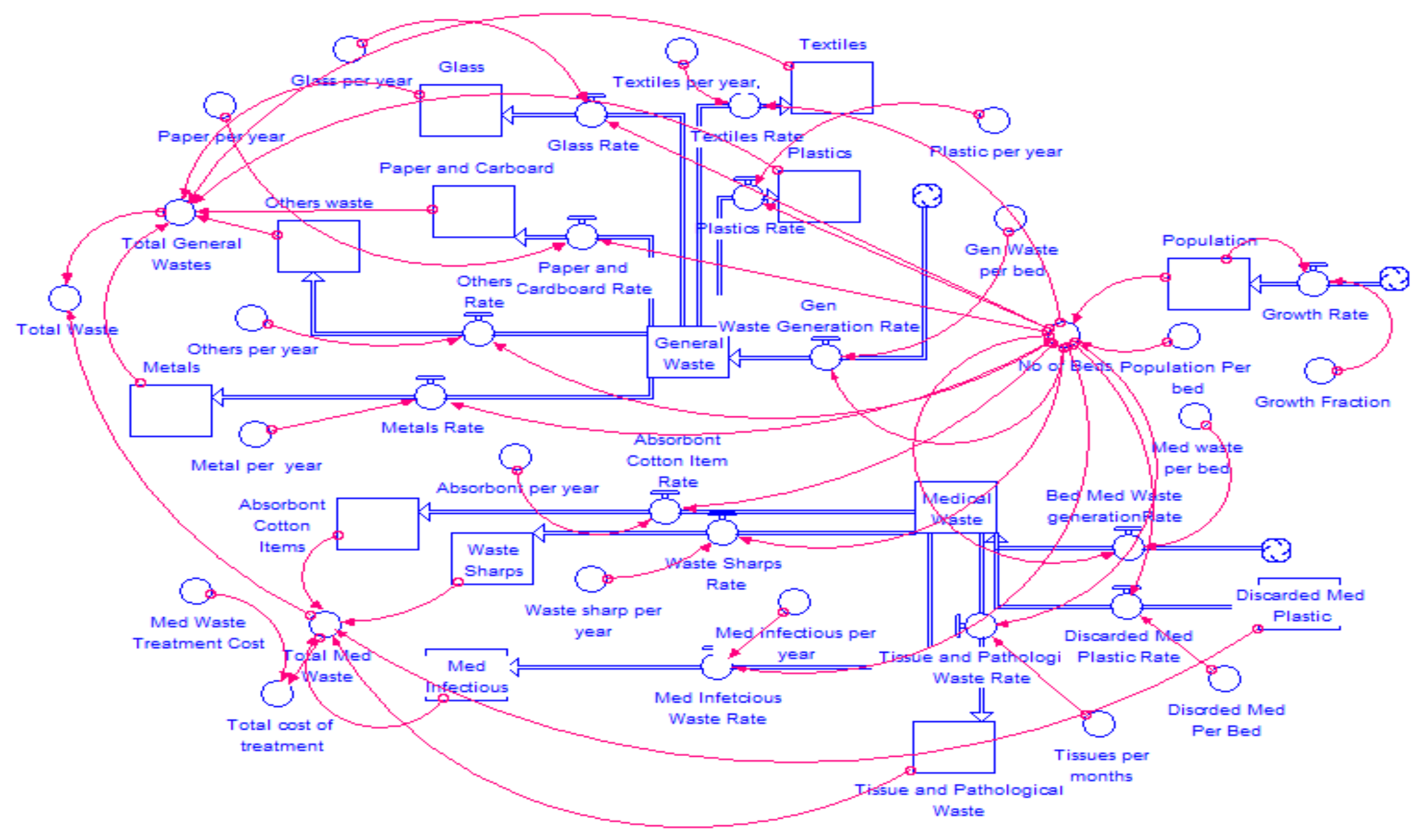

Figure 3. Hospital general and hospital wastehospital waste model 


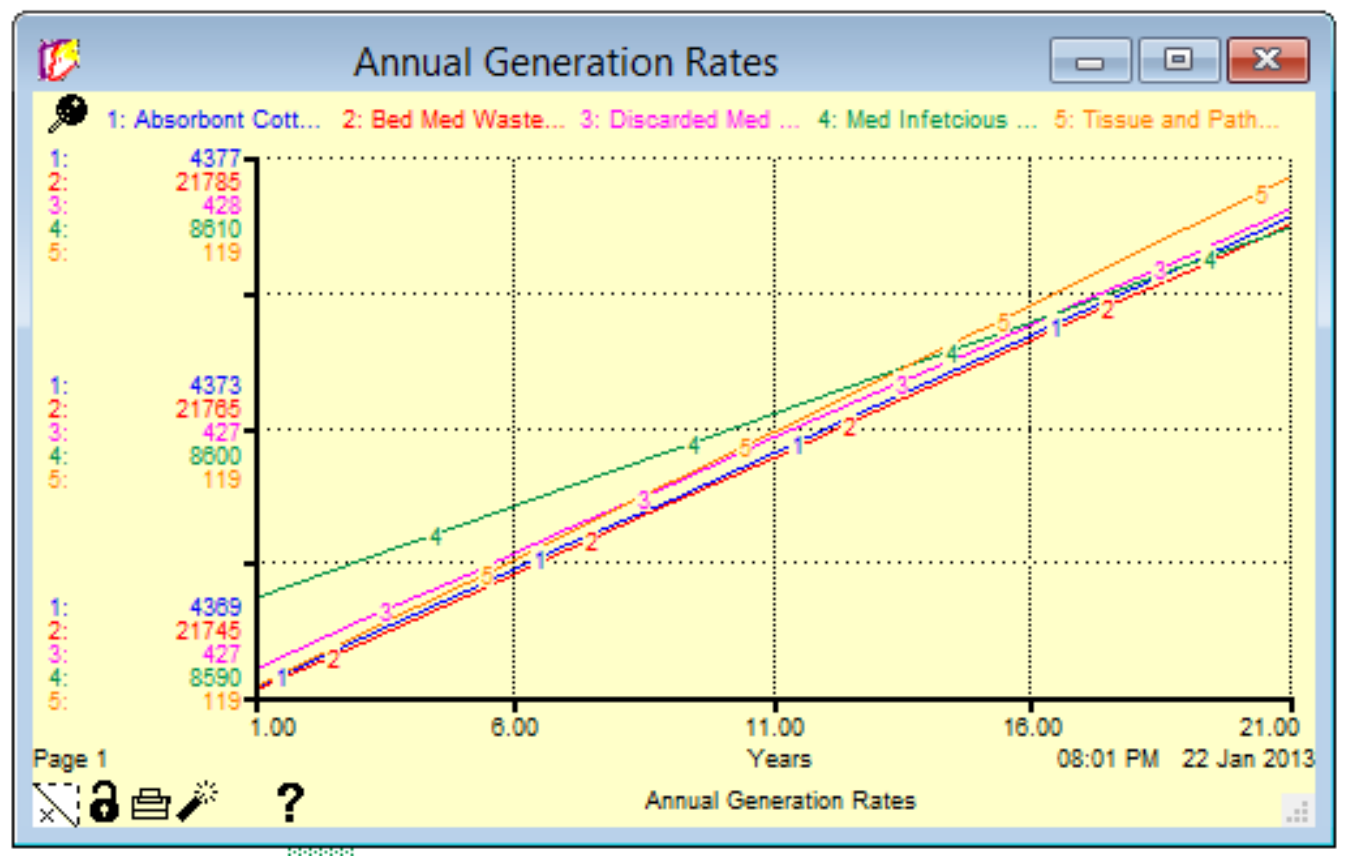

Figure 4. Annual Bed Hospital waste generation rate and its components (Kg/year) 
Table 1. Average hospital wastehospital waste generation rates in all surveyed hospitals

\begin{tabular}{lrrrrrrr}
\hline & \multicolumn{9}{c}{ Hospital wasteHospital waste components } & \\
\cline { 2 - 6 } & \multicolumn{8}{c}{$\begin{array}{c}\text { Waste } \\
\text { mixed } \\
\text { with } \\
\text { Generation rate }\end{array}$} & $\begin{array}{c}\text { Waste } \\
\text { sharps }\end{array}$ & $\begin{array}{l}\text { Patho- } \\
\text { infectious } \\
\text { waste }\end{array}$ & $\begin{array}{c}\text { Absorbent } \\
\text { cotton } \\
\text { items }\end{array}$ & $\begin{array}{c}\text { Discarded } \\
\text { medical } \\
\text { plastic }\end{array}$ & $\begin{array}{l}\text { Total } \\
\text { hazardous } \\
\text { healthcare } \\
\text { waste }\end{array}$ \\
\hline gm/bed/day & 25.7 & 17.8 & 426.8 & 133.1 & 243.9 & 847.3 \\
gm/in-patient/day & 61.1 & 42.4 & $1,013.7$ & 316.0 & 579.4 & $2,012.6$ \\
gm/total patients/day & 10.1 & 0.3 & 8.0 & 2.5 & 4.6 & 15.8 \\
gm/employee/day & 8.8 & 6.1 & 145.7 & 45.4 & 83.3 & 289.3 \\
\hline
\end{tabular}

Table 2. Average general waste generation rates in all surveyed hospitals

\begin{tabular}{lrrrrrrrr}
\hline \multirow{2}{*}{ Generation rate } & \multicolumn{4}{c}{ Type of general healthcare waste } & \multicolumn{2}{l}{$\begin{array}{l}\text { Total } \\
\text { general } \\
\text { healthcare } \\
\text { waste }\end{array}$} \\
\cline { 2 - 9 } & Plastics & Textiles & Glass & Metals & Paper & Others \\
\hline gm/bed/day & 371.5 & 19.9 & 27.8 & 5.0 & 357.2 & 334.7 & $1,116.0$ \\
gm/in-patient/day & 882.3 & 47.3 & 66.0 & 11.8 & 848.4 & 794.9 & $2,650.7$ \\
gm/total patients/day & 145.7 & 7.8 & 10.9 & 1.9 & 140.1 & 131.3 & 437.7 \\
gm/employee/day & 126.8 & 6.8 & 9.5 & 1.7 & 121.9 & 114.2 & 381.0 \\
\hline
\end{tabular}


Table 3. Average healthcare waste generation rates in all surveyed hospitals

\begin{tabular}{|c|c|c|c|}
\hline \multirow[b]{2}{*}{ Generation rate } & \multicolumn{2}{|c|}{ Category of hospital waste } & \multirow{2}{*}{$\begin{array}{c}\text { Total healthcare } \\
\text { waste }\end{array}$} \\
\hline & Total general & Total medical & \\
\hline gbed $^{-1}$ day $^{-1}$ & 11160 & 8472 & $1,963.3$ \\
\hline gtotal patients $^{-1}$ day $^{-1}$ & $2,650.7$ & $2,012.6$ & $4,663.4$ \\
\hline gin-patient $^{-1}$ day $^{-1}$ & 437.7 & 15.8 & 453.5 \\
\hline gemployee $^{-1}$ day $^{-1}$ & 381.0 & 289.3 & 670.2 \\
\hline
\end{tabular}

Table 4. Comparison of generation rate of hospital wastehospital waste in different countries

\begin{tabular}{lll}
\hline Country & $\begin{array}{l}\text { Generation rate } \\
\left(\text { Kg bed }^{-\mathbf{1}} \mathbf{d a y}^{\mathbf{1}} \mathbf{)}\right.\end{array}$ & References \\
\hline Brazil & $3.2-4.5$ & Da Silva et al. (2005) \\
China & 0.5 & Shen et al. (2003) \\
Greece & 1.9 & Tsakona et al. (2007) \\
Iran & $2.75-4.58$ & Taghipour and Mosaferi (2009); Askarian et al. \\
& & $(2004) ;$ Masoumbeigi et al. (2008);Farzadkia et al. \\
& & $(2009) ;$ Bazrafshan and Mostafapoor, 2011 \\
Jordan & 0.83 & Abdulla et al. (2008) \\
Libya & 1.3 & Sawalem et al. (2008) \\
Norway & 3.9 & Bdour et al. (2007) \\
Palestine & $1.86-2.3$ & Al-Khatib et al. 2009; Present study \\
Portugal & 3.9 & Diaz et al. (2008) \\
Spain & 4.4 & Bdour et al. (2007) \\
Taiwan & $2.41-3.26$ & Cheng et al. (2009) \\
Thailand & 1.0 & Kerdsuwan (2000) \\
Turkey & 0.63 & Birpinar et al. (2009)
\end{tabular}


Vietnam $\quad 1.42 \quad$ Diaz et al. (2008)

Table 5. Prediction of annual total, medical and general solid wastes (Kg/year)

\begin{tabular}{|c|c|c|c|}
\hline 23:27 & 20 Apr 2012 & able 6 (Table of Total Wa & 学? \\
\hline Years & Total Waste & Total Med Waste & Total General Wastes \\
\hline 1 & 0.00 & 0.00 & 0.00 \\
\hline 2 & $33,808.07$ & $14,189.54$ & $19,618.54$ \\
\hline 3 & $67,618.83$ & $28,380.20$ & $39,238.63$ \\
\hline 4 & $101,432.27$ & $42,571.99$ & $58,860.28$ \\
\hline 5 & $135,248.40$ & $56,764.91$ & $78,483.50$ \\
\hline 6 & $169,087.22$ & $70,958.95$ & $98,108.27$ \\
\hline 7 & $202,888.72$ & $85,154.12$ & $117,734.60$ \\
\hline 8 & $236,712.91$ & $99,350.42$ & $137,362.49$ \\
\hline 9 & $270,539.79$ & $113,547.85$ & $156,991.94$ \\
\hline 10 & $304,369.36$ & $127,746.41$ & $176,622.95$ \\
\hline 11 & $338,201.61$ & $141,946.09$ & $196,255.52$ \\
\hline 12 & $372,036.56$ & $156,146.91$ & $215,889.65$ \\
\hline 13 & $405,874.19$ & $170,348.85$ & $235,525.34$ \\
\hline 14 & $439,714.50$ & $184,551.92$ & $255,162.59$ \\
\hline 15 & $473,557.51$ & $198,756.12$ & $274,801.39$ \\
\hline 16 & $507,403.21$ & $212,961.44$ & $294,441.76$ \\
\hline 17 & $541,251.59$ & $227,167.90$ & $314,083.69$ \\
\hline 18 & $575,102.67$ & $241,375.48$ & $333,727.19$ \\
\hline 19 & $608,956.43$ & $255,584.20$ & $353,372.24$ \\
\hline Final & $642,812.89$ & $269,794.04$ & $373,018.85$ \\
\hline$i$ & $1 \square$ & & \\
\hline
\end{tabular}


Table 6. Total cost of treatment of Hospital waste (\$/year)

\begin{tabular}{|r|r|r|r|}
\hline \multicolumn{1}{|c|}{$21: 51$} & \multicolumn{3}{|c|}{ 28 Feb 2012 3 (Total Cost of treatment? } \\
\hline Years & Medical Waste & Total Med Waste & Total cost of treatment \\
\hline 1 & 0.00 & 0.00 & 0.00 \\
\hline 2 & $7,565.88$ & $14,189.54$ & $12,770.58$ \\
\hline 3 & $15,330.87$ & $28,790.57$ & $25,911.51$ \\
\hline 4 & $23,331.34$ & $43,815.03$ & $39,433.53$ \\
\hline 5 & $31,563.83$ & $59,275.20$ & $53,347.68$ \\
\hline 6 & $40,035.05$ & $75,183.72$ & $67,685.34$ \\
\hline 7 & $48,751.94$ & $91,553.58$ & $82,398.22$ \\
\hline 8 & $57,721.63$ & $108,398.17$ & $97,558.35$ \\
\hline 9 & $68,951.43$ & $125,731.25$ & $113,158.12$ \\
\hline 10 & $76,448.89$ & $143,586.99$ & $129,210.29$ \\
\hline 11 & $86,221.79$ & $161,919.97$ & $145,727.97$ \\
\hline 12 & $96,278.10$ & $180,805.18$ & $162,724.68$ \\
\hline 13 & $106,626.04$ & $200,238.07$ & $180,214.28$ \\
\hline 14 & $117,274.07$ & $220,234.51$ & $198,211.06$ \\
\hline 15 & $128,230.89$ & $240,810.84$ & $216,729.76$ \\
\hline 16 & $139,505.46$ & $261,983.89$ & $235,785.50$ \\
\hline 17 & $151,106.99$ & $283,770.96$ & $255,393.87$ \\
\hline 18 & $163,044.97$ & $306,189.85$ & $275,570.87$ \\
\hline 19 & $175,329.15$ & $329,258.90$ & $296,333.01$ \\
\hline Final & $187,969.57$ & $352,996.94$ & $317,697.24$ \\
\hline
\end{tabular}

